\title{
Cholangiopancreatoscopy: Expanding the Diagnostic Indications of Endoscopic Retrograde Cholangiopancreatography
}

\author{
Pedro Pereira, Pedro Costa-Moreira, Guilherme Macedo
}

Gastroenterology Department,

Centro Hospitalar e

Universitário São João,

Faculty of Medicine,

University of Porto,

Porto, Portugal

\author{
Address for correspondence: \\ Pedro Nuno Valente Reis \\ Pereira, MD \\ Gastroenterology Department, \\ Centro Hospitalar São João, \\ Porto \\ Al. Prof. Hernâni Monteiro \\ 4200 - 319 Porto, Portugal \\ pedro.pedroreispereira@gmail.com
}

Received: 18.03 .2020 Accepted: 19.06.2020

\begin{abstract}
Besides the adverse effects associated with endoscopic retrograde cholangiopancreatography (ERCP), indirect visualization of the biliopancreatic system through fluoroscopy has limited its diagnostic and therapeutic efficacy. Direct visualization through cholangiopancreatoscopy may overcome this limitation and allow the resolution of many dilemmas related to the diagnostic and therapeutic drawbacks of ERCP. Herein, we discuss the current indications of single-operator cholangioscopy (SOC) concerning the diagnostic interventions within the biliopancreatic system. The current role of SOC in the diagnosis of pancreatobiliary stenosis, primary sclerosing cholangitis, intraductal papillary mucinous neoplasm, and pre-surgical mapping of neoplastic lesions were reviewed. There is growing data in the literature supporting the early implementation of SOC in the diagnostic algorithm of pancreatobiliary diseases. In selected cases, this could prevent diagnostic delay and reduce the risks and costs related to repeated ERCPs. This potential characterizes SOC as safety and cost-effective.
\end{abstract}

Key words: cholangioscopy - pancreatobiliary neoplasia - biliary strictures - pancreatic intraductal papillary mucinous neoplasm.

Abbreviations: BD-IPMN: branch-duct intraductal papillary mucinous neoplasm; CP: chronic pancreatitis; ERCP: endoscopic retrograde cholangiopancreatography; EUS: endoscopic ultrasonography; FNA: fine-needle aspiration; IgG4-SC: IgG4-related sclerosing cholangitis; IPMN: intraductal papillary mucinous neoplasm; MD-IPMN: main duct IPMN; MRCP: magnetic resonance cholangiopancreatography; MPD: main pancreatic duct; PSC: primary sclerosing cholangitis; SOC: single-operator cholangioscopy.

\section{INTRODUCTION}

The introduction of endoscopic retrograde cholangiopancreatography (ERCP) was a significant advance in pancreatobiliary imaging. Endoscopic cannulation of the papilla de Vater was first reported in 1968 [1] and provided means of obtaining a detailed radiographic image of the biliary and pancreatic ducts. With the development of endoscopic sphincterotomy in 1974 [2, 3], ERCP evolved over the succeeding two decades with the addition of a multitude of therapeutic maneuvers. However, since its introduction, one of the significant drawbacks of ERCP is the potential adverse effects associated with the procedure. Therefore, the evolving role of ERCP has changed over the years with the emerging noninvasive or semiinvasive procedures.

Recent years brought a significant shift in ERCPs towards therapeutic indications and a decline in its conventional diagnostic utility [4]. Newer imaging modalities, in particular, magnetic resonance cholangiopancreatography (MRCP) and endoscopic ultrasonography (EUS) have provided detailed imaging of the bile and pancreatic ducts, thus expanding the field of pancreatobiliary imaging. EUS with fine-needle aspiration (FNA) is increasingly being used as a method for the diagnosis of pancreatic malignancy [5]. Beyond the introduction of imaging modalities, there are now better biomarkers in the blood, often making diagnostic ERCPs unnecessary. The former being particularly true in autoimmune pancreatitis or cholangitis. This imposing array of technology have provided different options for diagnosing and planning therapy in patients with pancreatobiliary disease, leaving primarily a therapeutic role to ERCP procedure. 
Besides the adverse effects associated with ERCP, indirect visualization of the biliopancreatic system through fluoroscopy has limited it's diagnostic and therapeutic efficacy. Direct visualization through cholangiospancreatoscopy may overcome this limitation especially in some arduous and challenging situations such as indeterminate stenosis and difficult stones [6, 7]. With the introduction of a single-operator cholangioscope (SOC) in 2007 [8], the technique has gained popularity and is increasingly performed by endoscopists worldwide with high success rates. This single-user device allows that a single physician can perform the procedure and it overcomes most of the shortcomings of the "mother-daughter scope", namely low image quality, lack of irrigation, small working channel, limited deflection ability and extreme fragility [9].

Most of the reported literature regarding SOC derives from the experience with the SpyGlass ${ }^{\mathrm{TM}}$ (Boston Scientific Corp, Natick, Massachusetts, USA). So this review will focus merely on different aspects of this platform. Initially, the system was made as a directable plastic sheath and a reusable optical combined light and image guide called SpyGlass ${ }^{\mathrm{TM}}$ Legacy. In 2015 , this system was replaced by an utterly disposable device with digital imaging (SpyGlass ${ }^{\mathrm{TM}} \mathrm{DS}$ ).

The purpose of this review is to discuss current indications of SOC concerning diagnostic interventions within the biliopancreatic system. The current role of SOC in the diagnosis of pancreatobiliary stenosis biliary, primary sclerosing cholangitis, intraductal papillary mucinous neoplasm and pre-surgical mapping of neoplastic lesions will be discussed. In the future, improving some features of SOC may change the current ERCP role in diagnosing pancreatobiliary neoplasia.

\section{DIAGNOSTIC APPLICATIONS OF CHOLANGIOSCOPY}

\section{Biliary strictures}

When dealing with a biliary stricture, the most crucial issue is to rule out malignancy. Obstruction of a bile duct may be due to lesions within the biliary lumen, from the bile duct itself, or extra-biliary compression.

Malignant biliary obstruction is most often due to cholangiocarcinoma or pancreatic adenocarcinoma. However, surgical series demonstrated that $15-24 \%$ of patients who undergo resection for suspected malignant strictures based on preoperative imaging or ERCP will ultimately have a benign diagnosis on pathology $[10,11]$. The benign causes of extrabiliary obstruction include compression from a gallstone lodged in the cystic duct (Mirrizi syndrome), benign cysts (hepatic, pancreatic, choledochal cysts), and vascular structures in the case of portal cholangiopathy. Regarding the intraluminal strictures, benign causes include autoimmune processes of primary sclerosing cholangitis (PSC) and IgG4related sclerosing cholangitis (IgG4-SC), responses to infection, vascular injuries, and the sequelae of iatrogenic or other trauma (e.g. long-standing choledocholithiasis) [12].

Due to this diversity of possible causes of biliary stenosis, and the therapeutic implications, the differential diagnosis of an incidentally discovered biliary stenosis is challenging. As an example, PSC accompanied by a stricture is a common dilemma; up to $26 \%$ of all patients with PSC strictures will develop cancer, a 400-fold increase over the general population [13]. Establishing a diagnosis in this setting is particularly challenging owing to the low sensitivity and negative predictive value of cytologic brushings [14].

Therefore it is essential to minimize the risk of surgically resecting a benign stricture or missing an opportunity to resect a curable malignancy. From a practical point of view, the term "indeterminate biliary stricture" refers to biliary strictures with no overt mass on noninvasive imaging such as computed tomography or MRCP, and which cannot be distinguished as malignant or benign after standard diagnostic procedures such as ERCP with tissue sampling (either brushing alone or in combination with biopsies) [15].

ERCP with tissue sampling and/or EUS-FNA is considered the mainstay in the evaluating of these lesions and excluding malignancy. EUS-FNA has a reported overall sensitivity between $43 \%$ and $86 \%$ for the diagnosis of all malignant strictures. However, it seems to be more sensitive in the evaluation of distal strictures, which are more often caused by pancreatic adenocarcinoma and more easily accessible for FNA sampling [16-19]. A diagnostic approach using SOC with biopsy or EUS-FNA according to the stricture location may be useful in the diagnosis of a suspected malignant biliary stricture. Unfortunately, there has been a lack of randomized controlled clinical trials comparing cholangioscopy-guided biopsy with EUS-guided tissue acquisition for the diagnosis of indeterminate biliary strictures. A prospective, observational study, conducted by Lee et al. [20], enrolled patients with a suspected malignant biliary stricture in whom a first ERCP with transpapillary forceps biopsy was not conclusive. In such cases, SOC and biopsy with SpyGlass ${ }^{\mathrm{TM}}$ system or direct per-oral colangioscopy using an ultraslim endoscope were performed for proximal strictures, and EUS-FNA was performed for distal strictures as a follow-up biopsy. The authors showed that the performance of cholangioscopy for proximal biliary strictures and EUS-tissue acquisition for distal biliary strictures had high sensitivities of $92.3 \%$ (95\%CI: 74.9-99.1) and 96.0\% (95\%CI: 79.7-99.9), respectively. However, despite the high accuracy, EUS-tissue acquisition of a primary bile duct tumor is currently contraindicated in patients who are potential candidates for liver transplantation [21].

In proximal lesions, ERCP with brush cytology and/or biliary biopsy is the current first-line approach. Although cholangiography provides clues to malignancy, such as complete obstruction, surface irregularity, and stricture length, these features cannot reliably distinguish the stricture's cause and thus obtaining tissue for histopathology remains the gold standard $[22,23]$. Despite a high specificity of brush cytology (>95\%), sensitivity remains an issue. A recent 10 -year experience review, including 16 studies, reported a pooled sensitivity of $41.6 \pm 3.2 \%$ for malignancy detection [24]. Given the low negative predictive value, the authors question the role of ERCP with brush cytology in changing the surgical management, especially in patients with a high suspicion of malignancy based on clinical, laboratory or imunological data.

Single-operator cholangioscopy offers a distinct advantage for the diagnosis of strictures allowing direct visualization of the lesion. The $3.3 \mathrm{~mm}$ outer diameter, continuous irrigation capability and four-way tip deflection allows the visualization of 
most of the lesions detected in fluoroscopy; however, a location in small intraductal branches or areas of seep angulation may be challenging to reach. In a recent review, comprising 691 patients, the ability to visualize and biopsy target lesions was achieved in $91,3 \%$ of the procedures [25]. High success rates (96\%) have also been reported in patients with PSC, in which multiple and fibrotic stenosis may limit cholangioscopy and a cholangioscopy guided sample [26] (Fig. 1).

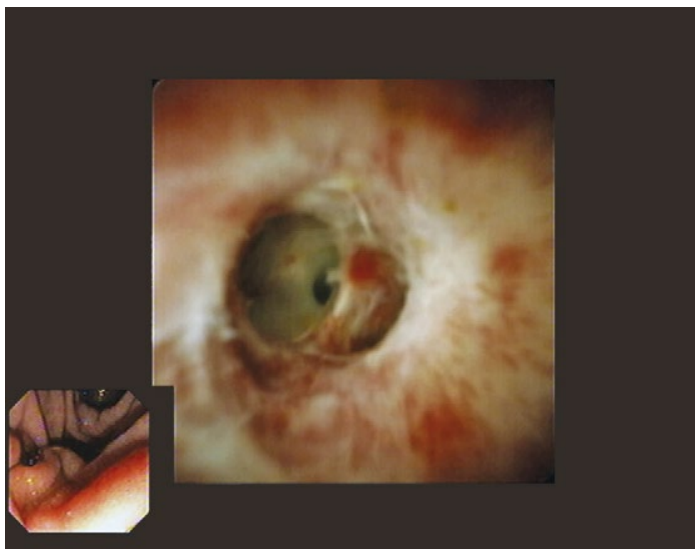

Fig. 1. Cholangioscopy in a primary sclerosing cholangitis patient with a "dominant stricture" identified in MRCP imaging. This method allowed the visualization of the stricture and direct tissue sampling for histologic evaluation.

Multiple cholangioscopic findings suggestive of malignancy have been identified in the literature, yet, there is currently no standard classification system for a truly visual diagnosis of malignancy (Table I). The most well-described predictor of malignancy appears to be the presence of a tumor vessel (tortuous and dilated vessel). Kim et al. [27] reported that the visualization of a tumor vessel had a sensitivity of $61 \%$ for the detection of malignancy and combination with cholangioscopy-guided biopsy increased sensitivity to $96 \%$. Other features such as intraductal masses and nodules, papillary/villous mucosal projections and ulceration have also been described as predictors of malignancy and can also help to predict the histological type of tumor [28]. In a multicenter prospective cohort study, Chen et al. [29] compared the sensitivity of ERCP to SOC impression for the detection of biliary malignancy in 95 patients. It was found that SOC had a sensitivity of $77.8 \%$ compared to $51.1 \%$ for ERCP.

Table I.

\begin{tabular}{l}
\hline Cholangioscopic features predictive of malignancy \\
\hline - Tumor vessel pattern \\
- Intraductal mass/nodule \\
- Pappilary/Vilous projections \\
- Mucosal ulceration \\
\hline
\end{tabular}

A systematic review evaluated the accuracy of visual cholangioscopic findings in determining the malignancy of biliary strictures [30]. Most of the studies used the fiberoptic imaging of the first-generation SpyGlass ${ }^{\mathrm{TM}}$, and the presence of a mass with tumor vessel for diagnosing malignancy. The sensitivity and specificity were found to be $84.5 \%$ and $82.6 \%$, respectively. Navaneethan et al. [31] recently reported an accuracy improvement with the use of SpyGlass ${ }^{\mathrm{TM}}$ DS; the authors prospectively evaluated 44 patients with indeterminate biliary stricture using the digital Image of the SpyGlass ${ }^{\mathrm{TM}}$ DS and reported a sensitivity of $90 \%$ and a specificity of $95.8 \%$. More recently, an observational cohort study by Jang et al. [32] aimed to measure the accuracy of SOC with SpyGlass ${ }^{\mathrm{TM}}$ DS in visual interpretation and bile duct sample of indeterminate biliary strictures. The study demonstrated that the addition of SOC could enhance the efficacy of ERCP in discerning malignant stricture from benign ones in a stricture that was once deemed indeterminate: the sensitivity of visual impression and bile duct sample was $89.1 \%$ and $69.8 \%$ and their specificity was $90 \%$ and $97.9 \%$, respectively. Also, the authors demonstrated that the degree of endoscopists' experience and the severity of hyperbilirubinemia negatively impacted the accuracy of SOC.

Diagnosing malignancy by visual impression, however, has some limitations: accuracy is limited when evaluating extrinsic strictures (such as pancreatic cancer, gallbladder cancer or metastatic disease) compared to cholangiocarcinoma, irregular patterns of biliary mucosa may not represent malignancy [8], pseudopolipoid morphology and traumatic ulcers can be seen after stent removal, and even traumatic lesions due to the passage of the scope may be misinterpreted. So visual impression is useful for detecting neoplastic lesions, but cholangioscopy-guided biopsy is required for confirmation.

The single operator colangioscop has a smaller $1.2 \mathrm{~mm}$ accessory channel that allows only the passage of a dedicated mini forceps (SpyBite ${ }^{\mathrm{TM}}$ Boston Scientific Corp, Marlborough, MA, USA). The biopsy cup of the mini forceps has a $4.1 \mathrm{~mm}$ opening at $55^{\circ}$ and a central spike for securing specimens in a difficult anatomy. Laleman et al. [25], in an aggregated review of 13 studies, reported a Spybite biopsy success and adequacy biopsy specimen of $94.2 \%$ and $82.3 \%$. The superiority of cholangioscopy-directed biopsy over standard ERCP cytology brushings was demonstrated in a prospective paired control design study of 26 patients with an indeterminate stricture [33]. Mini-forceps biopsy provided significantly better sensitivity $(76.5 \%$ vs. $5.9 \%, \mathrm{p}<0.0001)$ and overall accuracy ( $84.6 \%$ vs. $53.8 \%, p=0.0215$ ) compared with standard cytology brushings. A recent study by Gerges et al. [34] randomized patients with an indeterminate biliary stricture on the basis of MRCP to standard ERCP visualization with tissue brushing (control arm) or SOC with SOC-guided biopsy sampling. The study showed that the overall accuracy of SOC-guided biopsy samples was significantly higher than ERCP cytology brushing $(87.1 \%$ vs. $65.5 \%, \mathrm{p}<0.05)$, whereas specificity, positive predictive value and negative predictive value showed no significant difference. Also, adverse events were equally low in both arms.

Nevertheless, histologic diagnostic continues suboptimal, and some strategies have been described in order to improve it. Performing multiple intraductal biopsies, taking biopsies from the margin of the stenotic area [35], combination with ERCP conventional sampling [36] and rapid onsite evaluation of touch imprint cytology [37] can improve the sensitivity of cholangioscopy-directed biopsies. 
In 2018 a consensus document was published [21], aiming to provide evidence-based guidance to assist the selection of tissue diagnostic tools and improve the diagnostic yield for biliary strictures. This document supports that the selection of tissue diagnostic tools for biliary strictures depends on the clinical setting, tumor location and the availability of expertise. The consensus panel states that in the context of suspected biliary malignancy requiring an ERCP for biliary drainage, transpapillary standard biliary brushing and/or forceps biopsy are commonly performed as the first-line modality for sampling both distal and proximal biliary lesions. For a nondiagnostic first approach, the selection of endoscopic tissue diagnostic modality (SOC vs. EUS) should be determined by the location of the lesion and different clinical settings (Fig 2). A summary of the results of the cited articles regarding the diagnostic performance of SOC system is showed in Table II.

\section{Mapping of intraductal cholangiocarcinoma prior to resection}

Cholangiocarcinoma is an aggressive cancer that carries a poor prognosis. The surgical intervention combined with adjuvant or neoadjuvant therapies offers the highest chance for a cure, though only a minority of patients achieve this outcome. Often these tumors show extensive spread along the bile duct beyond the macroscopic extent of the visible mass [38]. This extension can result in tumor involvement at the resection margin after macroscopically successful radical resection. Single operator cholangioscopy has been used in the preoperative setting for diagnosing the lateral extent of cholangiocarcinoma (Fig. 3).

In a small case series from Japan [39], 20 patients with extrahepatic cholangiocarcinoma were evaluated preoperatively with SpyGlass ${ }^{\mathrm{TM}}$ DS for the lateral extent of cholangiocarcinoma. A visual impression of the intraepithelial spread was judged by referring to the following mucosal findings continuous from the primary tumor: (1) subtle irregular papillary or granular changes; (2) fine protrusions with so-called fish egg-like appearance; (3) vessels with irregularity in diameter; and (4) a line demarcating the height of the mucosa. Single operator cholangioscopy-guided mapping biopsy accuracy for preoperative diagnosis was $84 \%$ and $100 \%$, respectively for the liver side and the ampullary side. This oriental experience has recently been reproduced in a multicenter study, including various US centers and one European center [40]. In 118 patients with pancreatobiliary lesions, SOC changed the surgical plan in 32 patients with biliary lesions; 6 (5\%) had less extensive surgery and $26(25 \%)$ avoided surgery. The overall correlation between endoscopy and surgical histology was $88 \%$.

Together, these preliminary data suggest that SOC can delineate the degree of involvement in biliary lesions prior to surgical resection and could be used to determine resection lines in patients with extrahepatic cholangiocarcinoma, altering the surgical plan and optimizing patient care.

Inflammatory cholangiopathies: primary sclerosing cholangitis and IgG4-related sclerosing cholangitis

Primary sclerosing cholangitis is a chronic, cholestatic liver disease of uncertain etiopathogenesis which obstructs intra- and/or extrahepatic bile ducts via inflammation and fibro-obliteration [41]. The two most important issues in dealing with PSC is to rule out malignancy and the differential diagnosis with other inflammatory cholangiopathies, especially IgG4-SC. This increases the need for definitive diagnosis of biliary strictures in this patient population.

The indication for endoscopic intervention in PSC is most commonly to evaluate and/or treat "dominant strictures" or when MRCP is insufficient or unfeasible. In this context, cholangioscopy offers several potential clinical benefits: direct tissue sampling of strictures, identification of stones missed on cholangiography [42], comparing the visual characteristics of PSC to those of IgG4-SC and cholangiocarcinoma.

For excluding cholangiocarcinoma, SOC appears to be equally accurate in PSC and in patients with single biliary strictures. In a multicenter European study [43], including 52 PSC patients, the overall accuracy of SOC in differentiating between malignant and benign strictures was $88 \%$, and the accuracy of SOC guided biopsies was 79\%. Moreover, the reported experience in this population demonstrated a high technical success for targeted biopsies even in otherwise inaccessible strictures [26]. However, more disappointing accuracy results have been shown in a recent study [44]. In this retrospective single-center study [44] with a high proportion of PSC in the pool of indeterminate biliary stricture

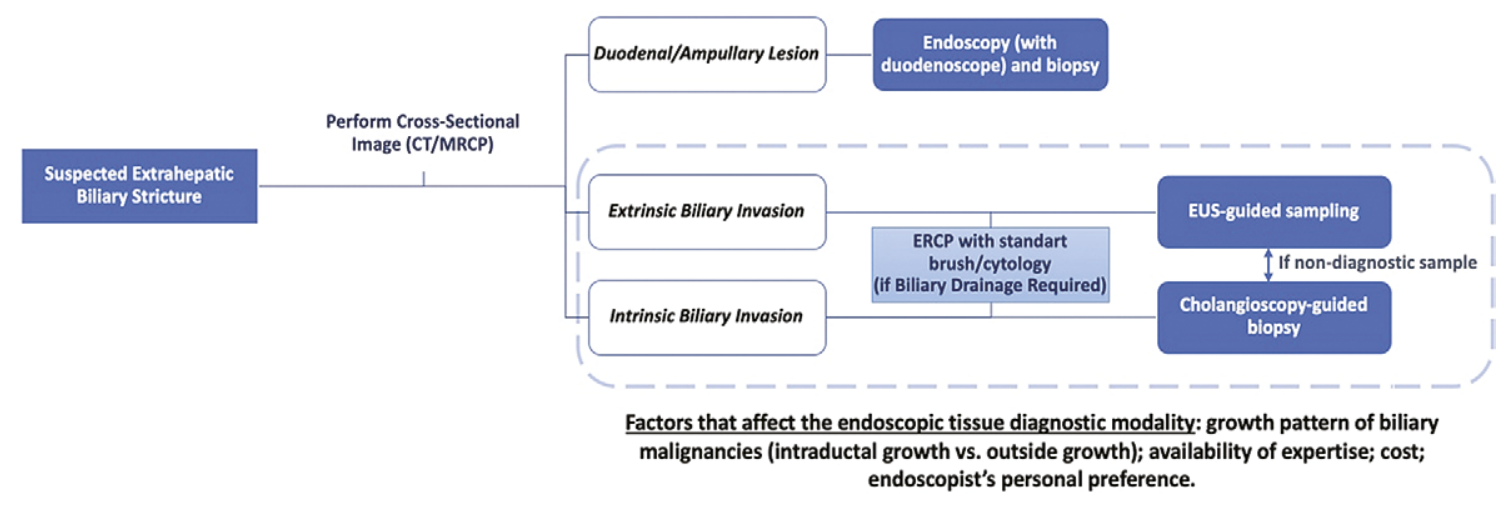

Fig. 2. Suggested algorithm for the evaluation and sampling of biliary strictures (adapted from Sun B et al. Aliment Pharmacol Ther 2018;48:138-51). Legend: CT: computed tomograohy; ERCP: endoscopic retrograde cholangiopancreatography; MRCP: magnetic resonance cholangiopancreatography. 
Table II. Results of the cited articles on overall diagnostic yield of SOC (and SOC-guided biopsies) for the evaluation of Indeterminate Biliary Strictures

\begin{tabular}{|c|c|c|c|c|c|c|c|c|c|c|c|}
\hline Study & Device & Design & $\mathrm{n}$ & Population & Outcome & Sensitivity & Specificity & PPV & NPV & Accuracy & $\begin{array}{l}\text { Adverse } \\
\text { Events }\end{array}$ \\
\hline $\begin{array}{l}\text { Lee et al., } \\
\text { [20] }\end{array}$ & 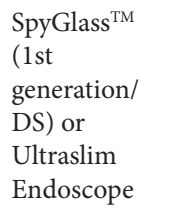 & $\begin{array}{l}\text { Observational, } \\
\text { Prospective }\end{array}$ & 32 & $\begin{array}{l}\text { Proximal } \\
\text { Biliary Stricture } \\
\text { with a previous } \\
\text { conventional } \\
\text { forceps biopsy } \\
\text { inconclusive }\end{array}$ & $\begin{array}{c}\text { Overall } \\
\text { Diagnostic } \\
\text { Accuracy }\end{array}$ & $92.3 \%$ & $100 \%$ & --- & --- & $93.6 \%$ & $6.3 \%$ \\
\hline \multirow[t]{2}{*}{$\begin{array}{l}\text { Laleman et } \\
\text { al. [25] }\end{array}$} & \multirow[t]{2}{*}{$\begin{array}{l}\text { SpyGlass } \\
\text { DS }\end{array}$} & \multirow[t]{2}{*}{$\begin{array}{l}\text { Observational, } \\
\text { Prospective }\end{array}$} & \multirow[t]{2}{*}{45} & \multirow{2}{*}{$\begin{array}{l}\text { Indeterminate } \\
\text { Biliary Stricture } \\
\text { submitted to } \\
\text { SOC (+ tissue } \\
\text { sampling) }\end{array}$} & $\begin{array}{c}\text { Visual } \\
\text { Interpretation }\end{array}$ & $83.3 \%$ & $82.9 \%$ & --- & --- & $82.9 \%$ & $21.4 \%$ \\
\hline & & & & & $\begin{array}{l}\text { SpyBite }^{\mathrm{TM}} \\
\text { Biopsies }\end{array}$ & $90.8 \%$ & $90.9 \%$ & --- & --- & $90.8 \%$ & \\
\hline \multirow[t]{2}{*}{$\begin{array}{l}\text { Chen et al., } \\
\text { [29] }\end{array}$} & \multirow{2}{*}{$\begin{array}{l}\text { SpyGlass }^{\mathrm{TM}} \\
\text { (1st } \\
\text { generation) }\end{array}$} & \multirow[t]{2}{*}{$\begin{array}{l}\text { Observational, } \\
\text { Prospective }\end{array}$} & \multirow[t]{2}{*}{95} & \multirow{2}{*}{$\begin{array}{l}\text { Indeterminate } \\
\text { Biliary Stricture } \\
\text { submitted to } \\
\text { SOC (+ tissue } \\
\text { sampling) }\end{array}$} & $\begin{array}{c}\text { Visual } \\
\text { Interpretation }\end{array}$ & $78 \%$ & $82 \%$ & $80 \%$ & $80 \%$ & $80 \%$ & $7.5 \%$ \\
\hline & & & & & $\begin{array}{l}\text { SpyBite }^{\mathrm{TM}} \\
\text { Biopsies }\end{array}$ & $49 \%$ & $98 \%$ & $100 \%$ & $72 \%$ & $75 \%$ & \\
\hline \multirow[t]{2}{*}{$\begin{array}{l}\text { Korrapati et } \\
\text { al., [30] }\end{array}$} & \multirow{2}{*}{$\begin{array}{l}\text { All Peroral } \\
\text { Cholangio- } \\
\text { scopy devices }\end{array}$} & \multirow{2}{*}{$\begin{array}{l}\text { Systematic } \\
\text { Review and } \\
\text { Meta-Analysis }\end{array}$} & \multirow[t]{2}{*}{$\begin{array}{c}49 \\
\text { studies }\end{array}$} & \multirow{2}{*}{$\begin{array}{l}\text { Indeterminate } \\
\text { Biliary Stricture } \\
\text { submitted to } \\
\text { SOC (+ tissue } \\
\text { sampling) }\end{array}$} & $\begin{array}{c}\text { Visual } \\
\text { Interpretation }\end{array}$ & $93 \%$ & $85 \%$ & --- & --- & $89 \%$ & $7 \%$ \\
\hline & & & & & $\begin{array}{l}\text { SpyBite }^{\mathrm{TM}} \\
\text { Biopsies }\end{array}$ & $69 \%$ & $94 \%$ & --- & --- & $79 \%$ & \\
\hline \multirow[t]{2}{*}{$\begin{array}{l}\text { Navaneethan } \\
\text { et al., [31] }\end{array}$} & \multirow[t]{2}{*}{$\begin{array}{l}\text { SpyGlass }^{\mathrm{TM}} \\
\text { DS }\end{array}$} & \multirow[t]{2}{*}{$\begin{array}{l}\text { Observational, } \\
\text { Prospective }\end{array}$} & \multirow[t]{2}{*}{44} & \multirow{2}{*}{$\begin{array}{l}\text { Indeterminate } \\
\text { Biliary Stricture } \\
\text { submitted to } \\
\text { SOC (+ tissue } \\
\text { sampling) }\end{array}$} & $\begin{array}{c}\text { Visual } \\
\text { Interpretation }\end{array}$ & $90 \%$ & $95.8 \%$ & $94.7 \%$ & $92.0 \%$ & --- & $2.9 \%$ \\
\hline & & & & & $\begin{array}{l}\text { SpyBite }^{\mathrm{TM}} \\
\text { Biopsies }\end{array}$ & $85 \%$ & $100 \%$ & $100 \%$ & $88.9 \%$ & $97.7 \%$ & \\
\hline \multirow[t]{2}{*}{$\begin{array}{l}\text { Jang et al., } \\
{[32]}\end{array}$} & \multirow[t]{2}{*}{$\begin{array}{l}\text { SpyGlass } \\
\text { DS }\end{array}$} & \multirow[t]{2}{*}{$\begin{array}{l}\text { Observational, } \\
\text { Prospective }\end{array}$} & \multirow[t]{2}{*}{105} & \multirow{2}{*}{$\begin{array}{l}\text { Indeterminate } \\
\text { Biliary Stricture } \\
\text { submitted to } \\
\text { SOC (+ tissue } \\
\text { sampling) }\end{array}$} & $\begin{array}{c}\text { Visual } \\
\text { Interpretation }\end{array}$ & $89.1 \%$ & $90 \%$ & $90.7 \%$ & $88.2 \%$ & $89.5 \%$ & $6.7 \%$ \\
\hline & & & & & $\begin{array}{l}\text { SpyBite }^{\mathrm{TM}} \\
\text { Biopsies }\end{array}$ & $69.8 \%$ & $97.9 \%$ & $97.4 \%$ & $74.6 \%$ & $83.2 \%$ & \\
\hline $\begin{array}{l}\text { Draganov et } \\
\text { al., [33] }\end{array}$ & $\begin{array}{l}\text { SpyGlass }^{\mathrm{TM}} \\
\text { DS }\end{array}$ & $\begin{array}{l}\text { Observational, } \\
\text { Prospective }\end{array}$ & 26 & $\begin{array}{l}\text { Indeterminate } \\
\text { Biliary Stricture } \\
\text { submitted to } \\
\text { SOC (+ tissue } \\
\text { sampling) }\end{array}$ & $\begin{array}{l}\text { SpyBite }^{\mathrm{TM}} \\
\text { Biopsies }\end{array}$ & $76.5 \%$ & $100 \%$ & --- & $69.2 \%$ & $84.6 \%$ & $11.5 \%$ \\
\hline $\begin{array}{l}\text { Gerges et } \\
\text { al., [34] }\end{array}$ & $\begin{array}{l}\text { SpyGlass }^{\mathrm{TM}} \\
\text { DS }\end{array}$ & $\begin{array}{l}\text { Randomized } \\
\text { Controlled } \\
\text { Trial }\end{array}$ & 32 & $\begin{array}{l}\text { Indeterminate } \\
\text { Biliary Stricture } \\
\text { submitted to } \\
\text { SOC (+ tissue } \\
\text { sampling) vs. } \\
\text { ERCP-guided } \\
\text { brushing }\end{array}$ & $\begin{array}{l}\text { SpyBite }^{\mathrm{TM}} \\
\text { Biopsies }\end{array}$ & $68.2 \%$ & $62.5 \%$ & $100 \%$ & $45.5 \%$ & $66.7 \%$ & $6.25 \%$ \\
\hline $\begin{array}{l}\text { Varadarajulu } \\
\text { et al., [37] }\end{array}$ & $\begin{array}{l}\text { SpyGlass }^{\mathrm{TM}} \\
\text { DS }\end{array}$ & $\begin{array}{l}\text { Observational, } \\
\text { Retrospective }\end{array}$ & 31 & $\begin{array}{l}\text { Indeterminate } \\
\text { Biliary Stricture } \\
\text { submitted to } \\
\text { SOC (+ tissue } \\
\text { sampling) }\end{array}$ & $\begin{array}{l}\text { SpyBite }^{\mathrm{TM}} \\
\text { Biopsies with } \\
\text { ROSE }\end{array}$ & $100 \%$ & $88.9 \%$ & $86.7 \%$ & $100 \%$ & $93.5 \%$ & $0 \%$ \\
\hline
\end{tabular}

ERCP: endoscopic retrograde cholangiopancreatography; NPV: negative predictive value; PPV: positive predictive value; ROSE - rapid nn-site evaluation; SOC: single operator cholangioscopy.

patients (32/80 patients). The diagnostic accuracy of SOC for indeterminate biliary strictures was found to be inferior to brush cytology, with a low impact on patient management (the outcome changed management in $17 \%$ of patients). The results of the study rekindle the discussion and, through some questioning, cast doubt on the true value of SOC with targeted biopsies in the diagnosis of indeterminate biliary strictures. However, these results reinforce the importance of other factors in the SOC procedure (bile duct size, multiple stenoses, fibrosis from previous stent therapy, tissue sampling and preparation, cytopathology expertise, etc) [45].
IgG4-SC has been recognized as a relatively new clinical entity, that contrary to PSC responds well to corticosteroid therapy. Serum IgG4 levels may be elevated in the two conditions, and there are no clinical or imaging characteristics that could differentiate PSC patients with normal IgG-4 levels from PSC patients with higher IgG4 levels [46]. In a study of 33 patients, Itoi et al. [47] compared the visual characteristics of PSC to those of IgG4-SC and cholangiocarcinoma. Scarring and pseudodiverticula were found significantly more often in PSC than IgG4-SC. In contrast, dilated vessels were found significantly more often in IgG4-SC than in patients with 


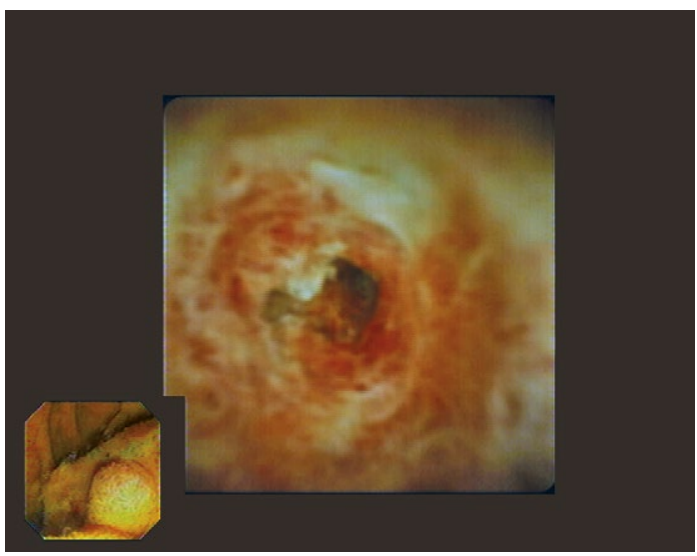

Fig. 3. Cholangioscopy in a patient with cholangiocarcinoma proposed for surgery. The visual impression of the intra-epithelial spread can delineate the proximal and distal extent of the lesion, determining the lateral extent of the tumor.

cholangiocarcinoma. Bile duct biopsies are not highly sensitive for diagnosing IgG4-SC since the infiltration of IgG4-positive plasma cells typically locates in the subepithelial region. Nevertheless, the use of cholangioscopy-guided forceps biopsy can accurately diagnose bile duct cancer and may help the distinction between these two conditions.

Adverse events appeared to occur more commonly following SOC in patients with PSC compared to controls, mainly due to an increased risk of post-procedural cholangitis in the former [43]. The intermittent ductal irrigation in the presence of a leak epithelium due to inflammation may explain the increased risk of cholangitis, reinforcing the need to correctly select the patients for the procedure and the universal administration of antibiotic prophylaxis in PSC patients submitted to SOC.

\section{DIAGNOSTIC APPLICATIONS OF PANCREATOSCOPY}

\section{Pancreatic Strictures}

Strictures of the main pancreatic duct (MPD) occur in chronic pancreatitis (CP) as a result of inflammation or fibrosis, or at anastomotic sites after pancreatic surgery. The presence of a dominant pancreatic stricture in the context of $\mathrm{CP}$ should raise the suspicions of occult malignancy, however differentiating between benign and malignant pancreatic duct strictures is often challenging using conventional imaging modalities. Similar to cholangioscopy, pancreatoscopy can be used in the diagnosis of pancreatic stricture, however, its role in the identification, evaluation, and sampling of occult pancreatic duct lesions remains limited to case series.

The most extensive experience reporting the use of pancreatoscopy for assessing pancreatic stenosis was recently reported by El Hajj et al. [48]. They evaluated in a retrospective analysis a 13-year experience of patients who underwent pancreatoscopy to evaluate an indeterminate pancreatic duct stricture or suspected intraductal papillary mucinous neoplasms (IPMN). A final diagnosis of neoplasia was established in $42 \%$ (33/79) patients included in the study (adenocarcinoma in 12 cases and IPMN in 21) [48]. The authors reported an $87 \%$ accuracy in distinguishing malignant for benign lesions (sensitivity $87 \%$, specificity $86 \%$ ) [48]. Lesions more frequently observed in patients with malignant lesions included: tumor vessels, mucin, ulceration, friability, infiltrative stricture, and protruding lesions including papillary, polypoid, villiform and vegetative lesions. Nevertheless, these results must be interpreted with caution as this report experience from a single US center with experience in pancreatic endotherapy. It is known that pancreatoscopy is technical more challenging due to the usual small diameter of the pancreatic duct, more tortuous course and the inability to visualize side branch lesions adequately.

Findings of smooth mucosa without protrusions, friability or tumor vessels are suggestive of benign stenotic lesions [48], yet pancreatoscopy directed tissue acquisition is needed for malignancy exclusion. Pancreatic stenosis usually are tight and fibrotic and developed in the context of CP with pancreatic stones in the pancreatic duct. Overall the advancement of the scope in the pancreatic duct as well as performing biopsies can be more complicated than in the bile duct. Dilatation of the stricture can help to obtain biopsies as reported in a case series of 5 patients with indeterminate pancreatic duct stenosis [49]. After dilation, the authors were able to obtain biopsies under direct visualization in 4 of the 5 patients (80\%), biopsies were benign in all the cases.

\section{Intraductal papillary mucinous neoplasm}

One of the indications of diagnostic pancreatoscopy is the characterization of IPMNs in terms of location, extent, and differentiating this entity from CP. IPMN is a lesion with papillary proliferation of mucin-producing neoplastic epithelium, which causes cystic dilation of the PD [50]. The entity is considered pre-malignant and involves a spectrum of epithelial changes ranging from hyperplasia to carcinoma [51].

The reported incidence of malignancy in main duct IPMN (MD-IPMN) is higher than of branch duct IPMN (BD-IPMN) [52]. Since MD-IPMN occurs predominately in the head of the pancreas, a region more easily accessed by pancreatoscopy, direct visualization of the lesion may help confirm the diagnosis in equivocal cases based on imaging and history. In particular, when there is diffusely dilated pancreatic duct without any focal lesions seen on cross-sectional imaging or EUS, or in the differential diagnosis of CP versus IPMN.

Trindade et al. [53] retrospectively evaluated 31 patients with dilated pancreatic duct; 13 patients $(42 \%)$ presented findings on pancreatoscopy that were not seen in other exams, including EUS. In these patients, pancreatoscopy dictated the type of surgery. Based on their results, the authors suggested a possible role for pre-surgical pancreatoscopy in patients with diffusely dilatated PD for evaluating lesions not evident in noninvasive evaluation.

In patients with non-dilated main pancreatic duct $(<5 \mathrm{~mm})$ pancreatoscopy may be more challenging. One study [54] reported the usefulness of pancreatoscopy using the SpyGlass ${ }^{\mathrm{TM}}$ probe in patients with non-dilated main pancreatic duct for evaluating IPMN. Pancreatoscopy was performed in 12 patients, and sufficient visualization was achieved in $92 \%$ of cases. Ten patients with protruding lesions were identified, but biopsies could only be obtained in seven due to the insufficient 
angulation of the probe. Targeted biopsies had a sensitivity of $25 \%$ and a specificity of $100 \%$. However, with pancreatoscopy irrigation cytology, they had a 100\% sensitivity and specificity for detecting malignancy.

Arnelo et al. [55] evaluated the role of pancreatoscopy in 44 patients suspected of IPMN based on radiological findings. Pancreatoscopy was considered to have affected the clinical decisions in $76 \%$ of the cases. Interestingly four of the 25 patients with radiological signs of MD-IPMN were classified as BD-IPMN after pancreatoscopy by the exclusion of lesions in the main pancreatic duct.

\section{Assessment of main pancreatic duct involvement in MD-IPMN}

To avoid total pancreatectomy, MD-IPMN can be treated with partial pancreatectomy if surgical margins are negative for high-grade dysplasia or invasive carcinoma [56]. Endoscopic ultrasound and other imaging modalities can detect mural nodules; however detecting intraductal low-length protruding lesion by EUS is quite difficult [56].

Pancreatoscopy can be used in the preoperative assessment of pancreatic duct involvement in MD-IPMN in order to "guide" surgical treatment in obtaining free surgical margins (Fig. 4). Two studies evaluated this issue [57, 58], but only one used the SpyGlass ${ }^{\mathrm{TM}}$ platform. In this small case series, the authors retrospectively analyzed data from seven patients who underwent a preoperative assessment of MD-IPMN using the digital version of SpyGlass ${ }^{\mathrm{TM}}$; the visualization of the target lesion was considered excellent. However, targeting biopsy had a poor diagnostic ability (sensitivity for diagnosing high-grade dysplasia was $0 \%$ ) and the intraoperative frozen section was still required to obtain a negative surgical margin [58].

Although previous reports [53,57] suggested that pancreatoscopy could guide the type of surgery, this technique may not be accurate enough in the preoperative assessment of the extent of main duct IPMN due to the poor diagnostic ability to target biopsy.

\section{Safety}

Since there are several noninvasive imaging modalities for evaluating the pancreatobiliary system, one of the major issues with SOC is safety. Clinical data shows that using SOC for diagnostic purposes augments the diagnostic accuracy of ERCP; nevertheless the possible rise in adverse effects may not overcome the clinical benefit derived from its use. Whether SOC adds significant additional risks to those associated with standard ERCP remains controversial.

In a large retrospective study by Sethi et al. [59] the authors compared the safety adverse of 3,476 ERCP with that of 402 cholangioscopies (using conventional cholangioscopes and first-generation SpyGlass ${ }^{\mathrm{TM}}$ ). The adverse events in the first group were $2.9 \%$ and in the second group $7 \%$. They detected significantly higher rates of cholangitis in the cholangioscopy group ( $1 \%$ vs. $0.2 \%)$ and similar rates of pancreatitis and perforation. This increase in complication was not observed in a single-center study [60]. Moreover, a meta-analysis of 45 studies on cholangioscopy demonstrated a pooled adverse event rate of 7\% (95\%CI: 6-9) and a pooled severe adverse event rate of $1 \%$ (95\%CI: $1-2)$ [30].
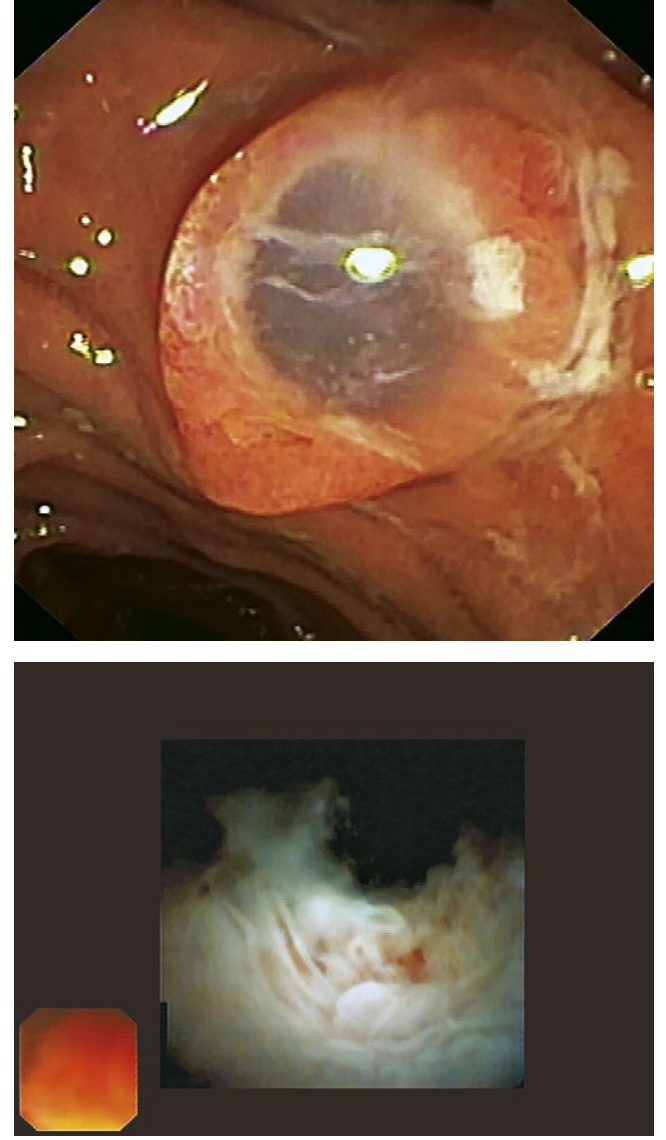

Fig. 4. Duodenoscopy (A) and Pancreatoscopy (B) in a case of a MD-IPMN proposed for surgical resection. Pancreatoscopy can delineate the extent of MD-IPMN and detect skip lesions of a diffusely dilated main pancreatic duct, guiding the choice of surgical procedure.

One explanation for the different reported rates of SOC adverse events could be the use of different definitions for complications and differences in the evaluated populations. Overall, SOC is considered a safe procedure with relatively few serious adverse events.

Limited irrigation of bile and pancreatic duct during the procedure, administration of prophylactic antibiotics and ensuring adequate drainage of duct explored may reduce the rate of cholangitis associated with SOC.

\section{CONCLUSIONS}

There is growing data in the literature supporting the early implementation of SOC in the diagnostic algorithm of pancreatobiliary strictures. In selected cases, this could prevent diagnostic delay and reduce the risks and costs related to repeated ERCPs.

Poor interobserver agreement of cholangioscopy images and lack of a correlation between the macroscopic features and histology can lead to misdiagnosis and limit the applicability of SOC in this clinical scenarios. The development of new classification system with good intra and interobserver agreement may improve the sensitivity of the visual diagnosis [61]. The use of chromoendoscopy and incorporating artificial 
intelligence systems for the interpretation of visual findings may help to solve the problem of suboptimal correlation between histological and macroscopic features. Indeed, this can reduce the problem of misdiagnosing malignancy in some vascular and pseudopolipoid lesions that may appear following stent removal.

Improvement of biopsy forceps and biopsy protocol is also needed since the achieved histological confirmation is still relatively low. Use of rapid onsite evaluation of touch imprint cytology [37] and ancillary cytologic techniques may increase the sensitivity of SpyBite biopsy forceps.

Incorporating SOC in the preoperative protocol of pancreatobiliary tumors may tailor and improve the efficacy of surgical treatment. Replication of published data in other centers through the elaboration of multicenter randomized control studies may help to define the precise role of SOC in the preoperative setting. Moreover, improving diagnostic ability with targeting biopsy may define the microscopic extension of the tumor and define surgical strategy previous to operation.

One of the major limitations of SOC dissemination has been the costs. In a recent study from two Belgian hospitals, the use of SOC determined a decrease in the number of procedures $(-31 \%$ relative reduction) and costs $(-€ 13$ $000 ;-5 \%$ relative variation) when compared with ERCP for indeterminate biliary strictures [62]. Preforming additional cost-effectiveness analysis may help to solve the problem of the high capital costs for the processor and the disposable catheter probe. Modifications in the reimbursement policy and creation of a dedicated code for SOC are additional measures that can be used for limiting the costs of the procedure. The clinical success though, has been widely acknowledged.

Conflicts of interest: None to declare.

Authors' contribution: P.P. and P.C.M. conceived and designed the study, revised the literature, drafted the manuscript. P.P., P.C.M. and G.M. critically revised the paper and approved the final version of the manuscript.

\section{REFERENCES}

1. McCune WS, Shorb PE, Moscovitz H. Endoscopic cannulation of the ampulla of vater: a preliminary report. Ann Surg 1968;167:752-756. doi:10.1097/00000658-196805000-00013

2. Classen M, Demling L. Endoscopic sphincterotomy of the papilla of vater and extraction of stones from the choledochal duct (author's transl). Dtsch Med Wochenschr 1974;99:496-497. doi:10.1055/s-0028-1107790

3. Kawai K, Akasaka Y, Murakami K, Tada M, Koli Y. Endoscopic sphincterotomy of the ampulla of Vater. Gastrointest Endosc 1974;20:148-151. doi:10.1016/s0016-5107(74)73914-1

4. Ahmed M, Kanotra R, Savani GT, et al. Utilization trends in inpatient endoscopic retrograde cholangiopancreatography (ERCP): A cross-sectional US experience. Endosc Int Open 2017;5:E261-E271. doi:10.1055/s-0043-102402

5. Chang KJ, Nguyen P, Erickson RA, Durbin TE, Katz KD. The clinical utility of endoscopic ultrasound-guided fine-needle aspiration in the diagnosis and staging of pancreatic carcinoma. Gastrointest Endosc 1997;45:387-393. doi:10.1016/s0016-5107(97)70149-4
6. Singh A, Gelrud A, Agarwal B. Biliary strictures: diagnostic considerations and approach. Gastroenterol Rep (Oxf) 2015;3:22-31. doi:10.1093/gastro/gou072

7. Yasuda I, Itoi T. Recent advances in endoscopic management of difficult bile duct stones. Dig Endosc 2013;25:376-385. doi:10.1111/den.12118

8. Chen YK, Pleskow DK. SpyGlass single-operator peroral cholangiopancreatoscopy system for the diagnosis and therapy of bile-duct disorders: a clinical feasibility study (with video). Gastrointest Endosc 2007;65:832-841. doi:10.1016/j.gie.2007.01.025

9. Nakajima M, Akasaka Y, Fukumoto K, Mitsuyoshi Y, Kawai K. Peroral cholangiopancreatosocopy (PCPS) under duodenoscopic guidance. Am J Gastroenterol 1976;66:241-247.

10. Clayton RA, Clarke DL, Currie EJ, Madhavan KK, Parks RW, Garden OJ. Incidence of benign pathology in patients undergoing hepatic resection for suspected malignancy. Surgeon 2003;1:32-38. doi:10.1016/s1479. 666x(03)80006-9

11. Gerhards MF, Vos P, van Gulik TM, Rauws EA, Bosma A, Gouma DJ. Incidence of benign lesions in patients resected for suspicious hilar obstruction. Br J Surg 2001;88:48-51. doi:10.1046/j.13652168.2001.01607.x

12. Novikov A, Kowalski TE, Loren DE. Practical Management of Indeterminate Biliary Strictures. Gastrointest Endosc Clin N Am 2019;29:205-214. doi:10.1016/j.giec.2018.12.003

13. Lindor KD, Kowdley KV, Harrison ME; American College of Gastroenterology. ACG Clinical Guideline: Primary Sclerosing Cholangitis. Am J Gastroenterol 2015;110:646-659. doi:10.1038/ ajg.2015.112

14. Levy MJ, Baron TH, Clayton AC, et al. Prospective evaluation of advanced molecular markers and imaging techniques in patients with indeterminate bile duct strictures. Am J Gastroenterol 2008;103:12631273.

15. Victor DW, Sherman S, Karakan T, Khashab MA. Current endoscopic approach to indeterminate biliary strictures. World J Gastroenterol 2012;18:6197-6205. doi:10.3748/wjg.v18.i43.6197

16. Rosch T, Hofrichter K, Frimberger E, et al. ERCP or EUS for tissue diagnosis of biliary strictures? A prospective comparative study. Gastrointest Endosc 2004;60:390-396. doi:10.1016/s00165107(04)01732-8

17. Lee JH, Salem R, Aslanian H, Chacho M, Topazian M. Endoscopic ultrasound and fine-needle aspiration of unexplained bile duct strictures. Am J Gastroenterol 2004;99:1069-1073.

18. Eloubeidi MA, Chen VK, Jhala NC, et al. Endoscopic ultrasoundguided fine needle aspiration biopsy of suspected cholangiocarcinoma. Clin Gastroenterol Hepatol 2004;2:209-213. doi:10.1016/s15423565(04)00005-9

19. Fritscher-Ravens A, Broering DC, Sriram PV, et al. EUS-guided fine-needle aspiration cytodiagnosis of hilar cholangiocarcinoma: a case series. Gastrointest Endosc 2000;52:534-540. doi:10.1067/ mge.2000.109589

20. Lee YN, Moon JH, Choi HJ, et al. Tissue acquisition for diagnosis of biliary strictures using peroral cholangioscopy or endoscopic ultrasound-guided fine-needle aspiration. Endoscopy 2019;51:50-59. doi:10.1055/a-0645-1395

21. Sun B, Moon JH, Cai Q, et al. Review article: Asia-Pacific consensus recommendations on endoscopic tissue acquisition for biliary strictures. Aliment Pharmacol Ther 2018;48:138-151. doi:10.1111/apt.14811

22. Bain VG, Abraham N, Jhangri GS, et al. Prospective study of biliary strictures to determine the predictors of malignancy. Can J Gastroenterol 2000;14:397-402. doi:10.1155/2000/467567 
23. Pasanen PA, Partanen KP, Pikkarainen PH, Alhava EM, Janatuinen EK, Pirinen AE. A comparison of ultrasound, computed tomography and endoscopic retrograde cholangiopancreatography in the differential diagnosis of benign and malignant jaundice and cholestasis. Eur J Surg 1993;159:23-29.

24. Burnett AS, Calvert TJ, Chokshi RJ. Sensitivity of endoscopic retrograde cholangiopancreatography standard cytology: 10-y review of the literature. J Surg Res 2013;184:304-311. doi:10.1016/j.jss.2013.06.028

25. Laleman W, Verraes K, Van Steenbergen W, et al. Usefulness of the single-operator cholangioscopy system SpyGlass in biliary disease: a single-center prospective cohort study and aggregated review. Surg Endosc 2017;31:2223-2232. doi:10.1007/s00464-016-5221-2

26. Arnelo U, von Seth E, Bergquist A. Prospective evaluation of the clinical utility of single-operator peroral cholangioscopy in patients with primary sclerosing cholangitis. Endoscopy 2015;47:696-702. doi:10.1055/s-0034-1391845

27. Kim HJ, Kim MH, Lee SK, Yoo KS, Seo DW, Min YI. Tumor vessel: a valuable cholangioscopic clue of malignant biliary stricture. Gastrointest Endosc 2000;52:635-638. doi:10.1067/mge.2000.108969

28. Seo DW, Lee SK, Yoo KS, et al. Cholangioscopic findings in bile duct tumors. Gastrointest Endosc 2000;52:630-634. doi:10.1067/ mge.2000.108667

29. Chen YK, Parsi MA, Binmoeller KF, et al. Single-operator cholangioscopy in patients requiring evaluation of bile duct disease or therapy of biliary stones (with videos). Gastrointest Endosc 2011;74:805-814. doi:10.1016/j.gie.2011.04.016

30. Korrapati P, Ciolino J, Wani S, et al. The efficacy of peroral cholangioscopy for difficult bile duct stones and indeterminate strictures: a systematic review and meta-analysis. Endosc Int Open 2016;4:E263-E275. doi:10.1055/s-0042-100194

31. Navaneethan U, Hasan MK, Kommaraju K, et al. Digital, singleoperator cholangiopancreatoscopy in the diagnosis and management of pancreatobiliary disorders: a multicenter clinical experience (with video). Gastrointest Endosc 2016;84:649-655. doi:10.1016/j. gie.2016.03.789

32. Jang S, Stevens T, Kou L, Vargo JJ, Parsi MA. Efficacy of digital singleoperator cholangioscopy and factors affecting its accuracy in the evaluation of indeterminate biliary stricture. Gastrointest Endosc 2020;91:385-393.e1. doi:10.1016/j.gie.2019.09.015

33. Draganov PV, Chauhan S, Wagh MS, et al. Diagnostic accuracy of conventional and cholangioscopy-guided sampling of indeterminate biliary lesions at the time of ERCP: a prospective, long-term followup study. Gastrointest Endosc 2012;75:347-353. doi:10.1016/j. gie.2011.09.020

34. Gerges C, Beyna T, Tang RSY, et al. Digital single-operator peroral cholangioscopy-guided biopsy sampling versus ERCP-guided brushing for indeterminate biliary strictures: a prospective, randomized, multicenter trial (with video). Gastrointest Endosc 2020;91:1105-1113. doi:10.1016/j.gie.2019.11.025

35. Tamada K, Kurihara K, Tomiyama T, et al. How many biopsies should be performed during percutaneous transhepatic cholangioscopy to diagnose biliary tract cancer? Gastrointest Endosc 1999;50:653-658 doi:10.1016/s0016-5107(99)80014-5

36. Tringali A, Lemmers A, Meves V, et al. Intraductal biliopancreatic imaging: European Society of Gastrointestinal Endoscopy (ESGE) technology review. Endoscopy 2015;47:739-753. doi:10.1055/s-0034-1392584

37. Varadarajulu S, Bang JY, Hasan MK, Navaneethan U, Hawes R, Hebert-Magee S. Improving the diagnostic yield of single-operator cholangioscopy-guided biopsy of indeterminate biliary strictures: ROSE to the rescue? (with video). Gastrointest Endosc 2016;84:681-687. doi:10.1016/j.gie.2016.03.1497

38. Weinbren K, Mutum SS. Pathological aspects of cholangiocarcinoma. J Pathol 1983;139:217-238. doi:10.1002/path.1711390210

39. Kanno Y, Koshita S, Ogawa T, et al. Peroral cholangioscopy by SpyGlass DS versus CHF-B260 for evaluation of the lateral spread of extrahepatic cholangiocarcinoma. Endosc Int Open 2018;6:E1349-E1354. doi:10.1055/a-0743-5283

40. Tyberg A, Raijman I, Siddiqui A, et al. Digital Pancreaticocholangioscopy for Mapping of Pancreaticobiliary Neoplasia: Can We Alter the Surgical Resection Margin? J Clin Gastroenterol 2019;53:71-75. doi:10.1097/ MCG.0000000000001008

41. Wiesner RH, LaRusso NF. Clinicopathologic features of the syndrome of primary sclerosing cholangitis. Gastroenterology 1980;79:200-206.

42. Awadallah NS, Chen YK, Piraka C, Antillon MR, Shah RJ. Is there a role for cholangioscopy in patients with primary sclerosing cholangitis? Am J Gastroenterol 2006;101:284-291

43. Kalaitzakis E, Sturgess R, Kaltsidis H, et al. Diagnostic utility of single-user peroral cholangioscopy in sclerosing cholangitis. Scand J Gastroenterol 2014;49:1237-1244. doi:10.3109/00365521.2014.93603 2

44. de Vries AB, van der Heide F, Ter Steege RWF, et al. Limited diagnostic accuracy and clinical impact of single-operator peroral cholangioscopy for indeterminate biliary strictures. Endoscopy 2020;52:107-114. doi:10.1055/a-1061-7067

45. de Moura EGH. Limited diagnostic accuracy and clinical impact of single-operator peroral cholangioscopy for indeterminate biliary strictures. Endoscopy 2020;52:90-91. doi:10.1055/a-1079-3569

46. Taghavi SA, Majd SK, Sianati M, Sepehrimanesh M. Prevalence of IgG-4associated cholangiopathy based on serum IgG-4 levels in patients with primary sclerosing cholangitis and its relationship with inflammatory bowel disease. Turk J Gastroenterol 2016;27:547-552. doi:10.5152/ tjg.2016.16344

47. Itoi $\mathrm{T}$, Kamisawa $\mathrm{T}$, Igarashi $\mathrm{Y}$, et al. The role of peroral video cholangioscopy in patients with IgG4-related sclerosing cholangitis. J Gastroenterol 2013;48:504-514. doi:10.1007/s00535-012-0652-6

48. El H, II, Brauer BC, Wani S, Fukami N, Attwell AR, Shah RJ. Role of per-oral pancreatoscopy in the evaluation of suspected pancreatic duct neoplasia: a 13-year U.S. single-center experience. Gastrointest Endosc 2017;85:737-745. doi:10.1016/j.gie.2016.07.040

49. Parbhu SK, Siddiqui AA, Murphy M, et al. Efficacy, Safety, and Outcomes of Endoscopic Retrograde Cholangiopancreatography With Per-Oral Pancreatoscopy: A Multicenter Experience. J Clin Gastroenterol 2017;51:e101-e105. doi:10.1097/MCG.0000000000000796

50. Cooper CL, O'Toole SA, Kench JG. Classification, morphology and molecular pathology of premalignant lesions of the pancreas. Pathology 2013;45:286-304. doi:10.1097/PAT.0b013e32835f2205

51. Lafemina J, Katabi N, Klimstra D, et al. Malignant progression in IPMN: a cohort analysis of patients initially selected for resection or observation. Ann Surg Oncol 2013;20:440-447. doi:10.1245/s10434012-2702-y

52. Tanaka M, Chari S, Adsay V, et al. International consensus guidelines for management of intraductal papillary mucinous neoplasms and mucinous cystic neoplasms of the pancreas. Pancreatology 2006;6:1732. doi:10.1159/000090023

53. Trindade AJ, Benias PC, Kurupathi P, et al. Digital pancreatoscopy in the evaluation of main duct intraductal papillary mucinous neoplasm: a multicenter study. Endoscopy 2018;50:1095-1098. doi:10.1055/a-0596-7374

J Gastrointestin Liver Dis, September 2020 Vol. 29 No 3: 445-454 
54. Nagayoshi Y, Aso T, Ohtsuka T, et al. Peroral pancreatoscopy using the SpyGlass system for the assessment of intraductal papillary mucinous neoplasm of the pancreas. J Hepatobiliary Pancreat Sci 2014;21:410-417. doi:10.1002/jhbp.44

55. Arnelo U, Siiki A, Swahn F, et al. Single-operator pancreatoscopy is helpful in the evaluation of suspected intraductal papillary mucinous neoplasms (IPMN). Pancreatology 2014;14:510-514. doi:10.1016/j. pan.2014.08.007

56. Tanaka M, Fernandez-Del Castillo C, Kamisawa T, et al. Revisions of international consensus Fukuoka guidelines for the management of IPMN of the pancreas. Pancreatology 2017;17:738-753. doi:10.1016/j. pan.2017.07.007

57. Navez J, Hubert C, Gigot JF, et al. Impact of Intraoperative Pancreatoscopy with Intraductal Biopsies on Surgical Management of Intraductal Papillary Mucinous Neoplasm of the Pancreas. J Am Coll Surg 2015;221:982-987. doi:10.1016/j.jamcollsurg.2015.07.451

58. Ohtsuka T, Gotoh Y, Nakashima Y, et al. Role of SpyGlass-DS(tm) in the preoperative assessment of pancreatic intraductal papillary mucinous neoplasm involving the main pancreatic duct. Pancreatology 2018;18:566-571. doi:10.1016/j.pan.2018.04.012

59. Sethi A, Chen YK, Austin GL, et al. ERCP with cholangiopancreatoscopy may be associated with higher rates of complications than ERCP alone: a single-center experience. Gastrointest Endosc 2011;73:251-256. doi:10.1016/j.gie.2010.08.058

60. Draganov PV, Lin T, Chauhan S, Wagh MS, Hou W, Forsmark CE. Prospective evaluation of the clinical utility of ERCP-guided cholangiopancreatoscopy with a new direct visualization system Gastrointest Endosc 2011;73:971-979. doi:10.1016/j.gie.2011.01.003

61. Robles-Medranda C, Valero M, Soria-Alcivar M, et al. Reliability and accuracy of a novel classification system using peroral cholangioscopy for the diagnosis of bile duct lesions. Endoscopy 2018;50:1059-1070. doi:10.1055/a-0607-2534

62. Deprez PH, Garces Duran R, Moreels T, et al. The economic impact of using single-operator cholangioscopy for the treatment of difficult bile duct stones and diagnosis of indeterminate bile duct strictures. Endoscopy 2018;50:109-118. doi:10.1055/s-0043-121268 